G. Hooss · R. Voss $\cdot$ K. Hasselmann

E. Maier-Reimer · F. Joos

\title{
A nonlinear impulse response model of the coupled carbon cycle-climate system (NICCS)
}

Received: 28 January 2000 / Accepted: 9 March 2001

\begin{abstract}
Impulse-response-function (IRF) models are designed for applications requiring a large number of climate change simulations, such as multi-scenario climate impact studies or cost-benefit integrated-assessment studies. The models apply linear response theory to reproduce the characteristics of the climate response to external forcing computed with sophisticated stateof-the-art climate models like general circulation models of the physical ocean-atmosphere system and three-dimensional oceanic-plus-terrestrial carbon cycle models. Although highly computer efficient, IRF models are nonetheless capable of reproducing the full set of climate-change information generated by the complex models against which they are calibrated. While limited in principle to the linear response regime (less than about $3{ }^{\circ} \mathrm{C}$ global-mean temperature change), the applicability of the IRF model presented has been extended into the nonlinear domain through explicit treatment of the climate system's dominant nonlinearities: $\mathrm{CO}_{2}$ chemistry in ocean water, $\mathrm{CO}_{2}$ fertilization of land biota, and sublinear radiative forcing. The resultant nonlinear impulse-response model of the coupled carbon cycle-climate system (NICCS) computes the temporal evolution of spatial patterns of climate change for four climate variables of particular relevance for climate impact studies: nearsurface temperature, cloud cover, precipitation, and sea level. The space-time response characteristics of the model are derived from an EOF analysis of a transient 850-year greenhouse warming simulation with the Hamburg atmosphere-ocean general circulation model
\end{abstract}

G. Hooss $(\varangle) \cdot$ R. Voss · K. Hasselmann · E. Maier-Reimer Max-Planck-Institut für Meteorologie, Bundesstrasse 55, 20146 Hamburg, Germany

E-mail: hooss@dkrz.de

F. Joos

Climate and Environmental Physics, Physics Institute, University of Bern, Sidlerstrasse 5, 3012 Bern, Switzerland
ECHAM3-LSG and a similar response experiment with the Hamburg carbon cycle model HAMOCC. The model is applied to two long-term $\mathrm{CO}_{2}$ emission scenarios, demonstrating that the use of all currently estimated fossil fuel resources would carry the Earth's climate far beyond the range of climate change for which reliable quantitative predictions are possible today, and that even a freezing of emissions to presentday levels would cause a major global warming in the long term.

\section{Introduction}

For comprehensive integrated assessment and other climate impact studies, computations of climate change are often required for a large number of greenhouse gas (GHG) emission scenarios. The most reliable instruments currently available for the estimation of anthropogenic climate change are coupled atmosphereocean general circulation models (AOGCMs) in combination with three-dimensional models of the carbon cycle and other, non- $\mathrm{CO}_{2}$ greenhouse gases. However, for multi-scenario investigations, these models are prohibitively expensive in computation time. Ideally, a climate model designed for application in integrated assessment and climate impact studies should provide the desired climate-change information without excessive computational cost, while nevertheless approaching the reliability and detail of sophisticated, top-of-the-line climate models.

While AOGCMs process a huge amount of information on the three-dimensional ocean-atmosphere system, only a small subset of the data is normally required as output to characterize the resulting climate change. One is interested typically only in some vector $x(t)$ representing, for example, the change in a set of twodimensional fields such as near-surface temperature, cloud cover, precipitation or sea level. As input characterizing the external anthropogenic forcing $f(t)$ one is 
similarly concerned only with low-dimensional fields, or even a scalar, like the globally integrated input of fossilfuel carbon dioxide into the atmosphere.

Provided the change relative to a reference climate state is small, the response of $x(t)$ to an arbitrary (but sufficiently small) forcing $f(t)$ is given generally by a convolution with the climate system's linear impulse response function (IRF) $R$ :

$x(t)=\int_{-\infty}^{t} R\left(t-t^{\prime}\right) f\left(t^{\prime}\right) \mathrm{d} t^{\prime}$.

The function $R(t)$ represents the response to a $\delta$-function forcing at time $t=0$. Once the IRF has been determined, for example by fitting to a single climate change simulation with a sophisticated climate model (or, in practice, to separate response experiments for the individual physical climate and greenhouse-gas modules from which the full climate model is constructed), the simple convolution (IRF) model can be applied to any time-dependent forcing scenario without further reference to the sophisticated climate model against which it was calibrated. As long as one remains within the linear regime, the IRF model then serves as an exact substitute for the full model.

In principle, IRF models can be designed to reproduce, without loss of information, any output from a sophisticated model, including annual cycles and derived quantities like extreme value statistics. They provide a highly efficient method of computing credible timedependent climate-change scenarios. For a single input variable, the cpu times are of the order of a second on a workstation. For a multidimensional input with $n_{f}$ independent degrees of freedom (as would be required, e.g., to describe spatially variable aerosol emissions), the cpu time increases linearly with $n_{f}$, and one requires $n_{f}+1$ GCM reference experiments (including a control run) to calibrate the model. In our applications, however, we shall consider only $\mathrm{CO}_{2}$ emissions as input. Since $\mathrm{CO}_{2}$ is well mixed in the atmosphere on the time scales relevant for climate change, the input can be characterized in this case by a single scalar variable representing the global integral of the $\mathrm{CO}_{2}$ emissions.

According to the linear-response-fitting exercises for oceanic $\mathrm{CO}_{2}$ uptake by Maier-Reimer and Hasselmann (1987), the linear response range for the carbon cycle is constrained to $\mathrm{CO}_{2}$ concentrations less than about twice the preindustrial value of $p \mathrm{CO}_{2, p}=280 \mathrm{ppm}$, corresponding to an equilibrium warming of less than about $3{ }^{\circ} \mathrm{C}$. This is consistent with the linear-response limits found by Hasselmann et al. (1993) in their analysis of the cold-start errors of global warming simulations with AOGCMs.

The goals of this study are twofold: to extend this range of applicability by including the main limiting nonlinear physical processes into an IRF-based model, and to generalize an earlier IRF model for global mean temperature, used by Hasselmann et al. (1997) in a coupled climate-socioeconomic model for the costbenefit analysis of optimal $\mathrm{CO}_{2}$ emission paths, to spa- tially dependent fields and other climate variables (cloudiness, precipitation, and sea level). The following nonlinearities are considered:

1. The solubility of additional $\mathrm{CO}_{2}$ in ocean surface water decreases with rising concentrations. This reduces the uptake of the mixed surface layer and thereby the downward transport from the mixed layer into the large deep-ocean reservoir.

2 . The net primary production of land vegetation, which is believed to act as a sink for anthropogenic carbon, is assumed to respond logarithmically to increasing atmospheric $\mathrm{CO}_{2}$ (Bacastow and Keeling 1973; Enting et al. 1994). This has been incorporated previously in a terrestrial biosphere model by Joos et al. 1996.

3 . The radiative greenhouse forcing increases only logarithmically with increasing $\mathrm{CO}_{2}$ concentrations, as the infrared absorption is already close to saturation in the principal $\mathrm{CO}_{2}$ absorption bands.

Caldeira and Kasting (1993) have pointed out that the higher $\mathrm{CO}_{2}$ concentrations resulting from the decrease in solubility tend to be compensated by the weaker logarithmic radiative forcing in the nonlinear system. Thus IRF models of the combined carbon-cycle and physical ocean-atmosphere system give a better linear approximation of the net response of the system than the IRF models of each of the subsystems separately. However, we find that the cancellation of nonlinearities is only partial. Furthermore, since the climate policy debate often focuses on $\mathrm{CO}_{2}$ concentrations rather than global warming scenarios, it is desirable to model each of the subsystems as accurately as possible.

In summary, the nonlinear impulse-response model of the coupled carbon cycle-climate system (NICCS) presented in the following is an extended version of the impulse response function (IRF) climate model used in the structural integrated assessment model (SIAM) by Hasselmann et al. (1997), augmented by nonlinear ocean carbon chemistry, a simple IRF representation of the terrestrial biosphere adapted from Joos et al. (1996), a logarithmic formulation of the radiative greenhouse forcing, and spatial patterns of change in four impactrelevant climate variables.

Comprehensive climate models used to compute the climate response to anthropogenic $\mathrm{CO}_{2}$ emissions normally consist of two modules: a carbon cycle module to compute the atmospheric concentration of $\mathrm{CO}_{2}$ for given $\mathrm{CO}_{2}$ emissions, and a coupled atmosphere-ocean general circulation model (AOGCM) to compute the climate change resulting from the change in atmospheric $\mathrm{CO}_{2}$ concentration. Our IRF model similarly consists of two IRF modules: a carbon-cycle (CarC) IRF module calibrated against a three-dimensional ocean carbon cycle model and augmented by a terrestrial biosphere model, and a physical-climate-change (CliC) IRF module calibrated against an AOGCM. The net NICCS (nonlinear impulse-response model of the coupled carbon cycleclimate system), comprising the CarC and CliC IRF 
modules, can be run in a coupled or sequential mode. In the experiments discussed later we have run the two IRF modules sequentially, as we found the temperature feedback to be relatively small (see also Maier-Reimer et al. 1996). For greater transparency in illustrating other more important features of the model, we have therefore preferred to neglect this effect.

A more complete representation of the climate feedback on the carbon cycle would need to include also the impact of a change in the ocean circulation on the physical carbon pump (the downwelling of $\mathrm{CO}_{2}$ enriched surface waters in the North Atlantic and Antarctica into the deeper ocean) and the biological pump (the downward transport of $\mathrm{CO}_{2}$ through the rain of decaying plankton), see Maier-Reimer et al. (1996) and Sarmiento et al. (1998). These feedbacks were found to partially cancel each other (Maier-Reimer and Hasselmann 1987) and were not included in the carbon cycle model against which our CarC IRF was calibrated. Also not activated in the computed response of the parent ocean carbon cycle model to anthropogenic emissions (although included inz the model) were marine biological processes, as the biological pump is limited by nutrients rather than $\mathrm{CO}_{2}$ and is thus insensitive to anthropogenic $\mathrm{CO}_{2}$ emissions. Other feedbacks which we have neglected, largely because of lack of reliable information, concern the impact of changes in temperature, water availability and other climatic factors on the terrestrial biosphere.

The study is organized as follows: the next section describes the carbon-cycle IRF module, consisting of the ocean and terrestrial components. The atmosphereocean climate IRF module is presented in Sect. 3, while applications of the coupled IRF model NICCS are discussed in Sect. 4. Section 5 summarizes the principal conclusions. Details of the ocean carbon cycle IRF are given in the Appendix.

\section{The carbon cycle module}

The carbon-cycle IRF module consists of two components: the ocean carbon cycle and a land vegetation module.

\subsection{The ocean carbon cycle}

A number of 3D ocean carbon cycle models have been developed to compute the oceanic uptake of $\mathrm{CO}_{2}$, for example the Hamburg Model (HAMOCC1, Maier-Reimer and Hasselmann 1987) or the Princeton Model (Sarmiento et al. 1992; Sarmiento and Sundquist 1992; Siegenthaler and Sarmiento 1993). For changes in the atmospheric $\mathrm{CO}_{2}$ concentration less than a factor of about 2, most $3 \mathrm{D}$ ocean carbon cycle models can be characterized by their linear IRFs $\hat{R}_{c}(t)$ (Maier-Reimer and Hasselmann 1987).

Linear IRF models of the oceanic carbon uptake have been developed and applied e.g. by Siegenthaler and Oeschger (1978), Oeschger and Heimann (1983) and Siegenthaler (1983). We base our nonlinear IRF model on a linear impulse response representation of HAMOCC by Maier-Reimer and Hasselmann (1987). Their linear IRF model has previously been used for estimating future atmospheric $\mathrm{CO}_{2}$ e.g. by Harvey (1989) and for incorporation in a coupled climate-socioeconomic model (SIAM: structural integrated assessment model) by Hasselmann et al. (1997).
Since the advective and diffusive transport within the ocean is essentially linear (unless the circulation is significantly changed through feedback from the climate change), the accuracy of the linear approximation is limited only by the nonlinear uptake of $\mathrm{CO}_{2}$ through the ocean surface, which is governed by the chemical dissociation equilibrium relating the $\mathrm{CO}_{2}$ partial pressure $p \mathrm{CO}_{2}$ to the concentration of dissolved inorganic carbon (DIC) in the nearsurface water. At higher concentrations, additional carbon becomes less soluble, and thus a smaller amount of surface-water carbon for a given increase of $p \mathrm{CO}_{2}$ is available for mixing down into the deep ocean by thermohaline overturning (Maier-Reimer and Hasselmann 1987; Joos et al. 1996).

A successful attempt to circumvent the limitation of ocean carbon cycle IRF models to small perturbations was made by Joos et al. (1996). An IRF representation was used to describe the linear mixing and transport processes within the ocean, while the nonlinear air-sea exchange was modelled by a differential equation. The explicit formulation of the gas exchange not only extended the range of applicability to greater concentrations, but enabled also the model to be applied to all conservative tracers with sources and sinks in the atmosphere, like bomb radiocarbon or even (for small temperature changes) the oceanic heat uptake. Although requiring only modest CPU resources, the IRF substitute model reproduced the response of spatially resolving models to within a few percent, both for a wide range of carbon emission scenarios and for the uptake of bomb radiocarbon. However, the computational efficiency of the model was compromised by two factors: the need for two nested time-step loops (due to the differential treatment of the nonlinear air-sea exchange and the separate integral treatment of transport and diffusion), and, for very high anthropogenic $\mathrm{CO}_{2}$ emission scenarios $\left(p \mathrm{CO}_{2}>2000 \mathrm{ppm}\right)$, by the inelasticity of the air-sea exchange, which required very short time steps for the differential mixed-layer computations.

\subsection{The composite atmosphere-plus-mixed-layer system}

In principle, the limitation to small time steps can be overcome by using an implicit integration method. However, for a nonlinear system, this requires time-consuming iterations. Alternatively, the problem can be circumvented by regarding the mixed-layer-plusatmosphere subsystem as equilibrated with respect to $\mathrm{CO}_{2}$ exchange. This is permissible if the relevant time scales of climate change are long compared with the equilibration time of the mixed layer-plus-atmosphere subsystem (termed in the following simply the composite layer). The transport of $\mathrm{CO}_{2}$ through the surface needs then no longer to be modelled by a dynamical equation, so that the shortest time-scale is suppressed and the model can be integrated with significantly longer time steps.

The composite-layer IRF can be obtained by supression of the shortest time scale component of the atmospheric IRF of the parent model (see Maier-Reimer and Hasselmann 1987), which describes the atmosphere-mixed layer equilibration process, with subsequent renormalization of the reduced model. However, in its standard convolution-integral form the composite-layer IRF model is not suitable for the incorporation of the non-linear chemistry governing the oceanic $\mathrm{CO}_{2}$ uptake. For this purpose, the model needs to be translated into an equivalent differential representation that is physically interpretable in terms of the carbon capacities of the two subsystems of the composite-layer, the atmosphere and mixed layer. This can be achieved by constructing a box-model analogue of the IRF model in the form of a cascade of layers which are coupled through carbon fluxes proportional to the differences in the layer concentrations. Anthropogenic $\mathrm{CO}_{2}$ emissions are introduced into the uppermost or zeroth layer, which represents the composite atmosphere-plus-mixed-layer system. The $\mathrm{CO}_{2}$ input into the composite layer is distributed quasi-instantaneously between the atmosphere and the mixed layer, and the composite layer is then coupled to the rest of the ocean via its mixed-layer subsystem, which is in contact with the next-deeper layer.

The cascade's parameters (layer thicknesses and Newtonian relaxation coefficients) are chosen such that the uppermost (com- 
posite) layer's IRF matches the composite-layer IRF derived from the parent 3D model's atmospheric response (see Appendix for the model equations and tuning conditions). The decomposition of the uppermost (composite) layer into its atmospheric and mixed-layer subsystems is chosen such that the ratio of carbon uptake into the sublayers is in accord with the preindustrial mixed-layer buffer factor (Revelle and Suess 1957) for small perturbations. Once the linear cascade has been tuned in this way, the atmospheric and mixed-layer fractions for a larger change in the composite-layer carbon content $c_{0}$ are computed as nonlinear functions of $c_{0}$ from the nonlinear chemical equilibrium governing the relation between partial pressure and total inorganic carbon concentration in sea water, following Maier-Reimer and Hasselmann (1987).

\subsection{Calibration}

Our ocean carbon-cycle IRF is a recent least-squares fit to the HAMOCC3i (inorganic) response to a sudden increase of the atmospheric $\mathrm{CO}_{2}$ concentration by $1 \%(2.78 \mathrm{ppm})$. The model was run without a biological pump and without $\mathrm{CaCO}_{3}$ sediment interaction. The asymptotic airborne fraction $(13 \%)$ is close to the value found for the 1987 HAMOCC1 IRF (14\%; the small difference can be attributed to the onset of a nonlinear effect due to the different impulse sizes used for the two calibrations).

The nonlinear IRF model was checked, using values for the chemical equilibrium constants corresponding to the present-day global-mean temperature, against the full HAMOCC3i's response for impulses in which the preindustrial atmospheric $\mathrm{CO}_{2}$ was increased by $1 \%, 25 \%, 100 \%$, and $300 \%$ (Fig. 1 and Table 1 ).

For the largest impulse, the $\mathrm{CO}_{2}$ uptake of the nonlinear IRF module is a few percent slower than in HAMOCC3i: the nonlinear retardation of the carbon uptake is slightly overestimated. However, small errors in this range are to be expected, as the nonlinear air-sea exchange in the $3 \mathrm{D}$ model is spatially dependent and cannot be accurately simulated by a one-dimensional model using only a single set of global-mean chemistry and mixed-layer parameters.

The direct reduction in oceanic carbon uptake by sea surface warming through temperature-related chemistry changes only is

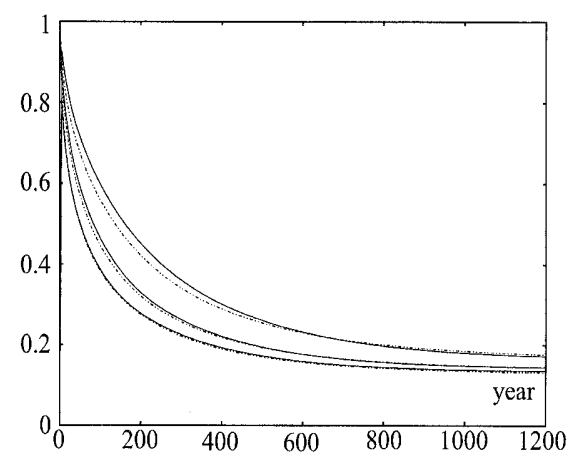

Fig. 1 Nonlinear impulse-response of the nonlinear ocean-carbon cycle IRF model (NO, solid lines) compared with its parent 3D model HAMMOC3i (dot-dot-dashed) to impulses increasing the preindustrial atmospheric $\mathrm{CO}_{2}$ content by $1 \%$ (lowest), $100 \%$ (medium), and $300 \%$ (highest curve), respectively. Only the perturbations are shown, normalized to the impulse size

Table 1 Amplitudes and time constants for the oceanic $\mathrm{CO}_{2}$ uptake IRF $\hat{R}_{c}$. computed from a least-squares fit to the HAMOCC $3 \mathrm{i}$ response to a sudden $1 \%$ increase of its preindustrial atmospheric $\mathrm{CO}_{2}$ (see Fig. 1)

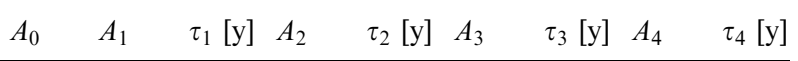

$\begin{array}{llllllllll}R 01 & 0.132 & 0.311 & 236.5 & 0.253 & 59.52 & 0.209 & 12.17 & 0.095 & 1.271\end{array}$ consistently estimated by different global warming-marine carbon cycle studies (e.g. Sarmiento et al. 1998; Matear and Hirst 1999; Joos et al. 1999; Plattner et al. 2001). However the total reduction of oceanic carbon uptake through all climate feedbacks combined, (including modifications of the thermohaline overturning circulation) is hard to predict even with respect to the sign. There is almost no agreement between different climate models. Predictions of the THC range from a complete switch-off, especially of the Atlantic THC, up to a slight enhancement. The majority of models predict a moderate reduction. Clearly, such a reduction, if not compensated by Antarctic deep water, would cause a weakening of the downward transport of $\mathrm{CO}_{2}$; it would, however, also reduce the upwelling of nutrient- and DIC-rich water to the surface. In high latitudes, the reduction of deep mixing would make the conditions for biological production more favourable (as the production takes place in the euphotic zone) and thus enhance the regional downward transport through the biological pump. Globally, changes in the biological cycle could lead to a transient increase or also decrease of the oceanic carbon uptake. Acting in opposite directions, the combined climate-induced changes in circulation, chemistry and biology were found in various studies to induce rather marginal modifications of the oceanic $\mathrm{CO}_{2}$ uptake in the range between $-7 \%$ and $+7 \%$ (Maier-Reimer et al. 1996; Joos et al. 1999; Matear and Hirst 1999; Plattner et al. 2001). A stronger decrease $\left(-35 \%\right.$ in the uptake rate at $4 \times \mathrm{CO}_{2}$, and the integral amounting to $-10 \%$ at $2 \times \mathrm{CO}_{2}$, or $-20 \%$ at $4 \times \mathrm{CO}_{2}$ ) was simulated by Friedlingstein et al. (2001). Thus, our uncertainties in the oceanic $\mathrm{CO}_{2}$ uptake are comparable to uncertainties in the present understanding of the surface-to-deep transport rates.

\subsection{The terrestrial biosphere module}

A $\mathrm{CO}_{2}$ sink of roughly $2 \mathrm{GtC} /$ year in the global terrestrial biosphere is believed to approximately compensate carbon losses from deforestation and other land use changes, mainly in the tropics. The allocation is ascribed to accelerated plant growth due to the rising $\mathrm{CO}_{2}$ concentrations $\left(\mathrm{CO}_{2}\right.$ fertilization) and nitrate fertilization. The efficiency of the terrestrial carbon sink and the question whether it will counteract fossil-fuel emissions in the future is hotly debated. Despite numerous papers on this topic in recent years (see e.g. the review of Schlesinger 1993; IPCC 1990; 1995; Tans et al. 1990; Keeling and Shertz 1992; Friedlingstein et al. 1995; Keeling et al. 1996; Sellers et al. 1996; Knorr 1997; Gayler and Claussen 1997; Joos and Bruno 1998; Claussen et al. 1999; Ganopolski et al. 1998 and many others), the issue is still far from resolved. Terrestrial biosphere models of different complexity and spatial resolution have been mapped onto $\mathrm{CO}_{2}$ uptake impulse response function models or equivalent box-type analogues (Meyer et al. 1999; Thompson and Randerson 1999).

We augmented our ocean carbon cycle module by a simple four-box representation of the terrestrial biosphere (Siegenthaler and Oeschger 1987), to account to first order for changes in the terrestrial carbon storage under rising $\mathrm{CO}_{2}$. The global terrestrial net primary production (NPP) is assumed to be proportional to the logarithm of the atmospheric $\mathrm{CO}_{2}$ concentration, and the respiratory $\mathrm{CO}_{2}$ flux back into the atmosphere is linear in the four reservoir contents (Joos et al. 1996; Kicklighter et al. 1999). Like other current terrestrial carbon cycle models, our terrestrial biosphere model neglects the effects of land-use changes and other interference and corresponding losses of biological diversity and productivity. It neglects furthermore complete NPP saturation even at high $\mathrm{CO}_{2}$ levels, and it neglects an accelerated respirative return of carbon to the atmosphere as is expected in a warmer climate. It is possible that these additional feedbacks would reduce the terrestrial $\mathrm{CO}_{2}$ uptake.

The aggregate model of the terrestrial carbon cycle is tuned to match estimates of the terrestrial carbon sink during the $1980 \mathrm{~s}$ (Schimel et al. 1997). When driven by emission scenarios, its response in terrestrial $\mathrm{CO}_{2}$ uptake was well within the range obtained with current, spatially resolved models (Kicklighter et al. 1999). 


\section{The climate change module}

In addition to the carbon-cycle (CarC) IRF module, we require as second component of our IRF model an IRF representation of the physical coupled atmosphere-ocean climate system. This was calibrated against the Hamburg AOGCM, as described in Hasselmann et al. (1993, 1997) Cubasch et al. (1992). However, in contrast to these applications, we consider now not only the global mean temperature as climate-change index, but generalize the climate change $(\mathrm{CliC}) \mathrm{IRF}$ representation to include four representative two-dimensional fields: near-surface temperature $\left(T_{2 m}\right)$, cloud cover (clo), precipitation (pre), and sea level (sea).

Schlesinger et al. (1998) proposed a procedure for combining a number of fixed spatial patterns with time-dependent coefficients in which the spatial patterns were derived from several equilibrium climate change simulations with a coupled atmospheric generalcirculation/mixed-layer-ocean model, while the trajectories of the corresponding time-dependent coefficients were computed by an energy-balance-climate/upwelling-diffusion-ocean model. Although this provides a number of spatial patterns and dynamic responses which can be combined to describe the net responses to different forcing mechanisms (greenhouse gases and direct sulfate aerosol forcing, for example), the spatial signals and temporal evolutions were derived from different models and were therefore not necessarily consistent. Furthermore, the parent models were strongly simplified in at least one of their components (atmosphere or ocean) and were thus less reliable with respect to the net spatiotemporal response than a fully coupled AOGCM. However, the validity of a separation of variables into spatial patterns of change with associated time-dependent factors has been confirmed by other authors, see Huntingford and Cox (2000) and citations therein.

Huntingford and Cox (2000) reproduced decade-averaged global mean changes in a number of impact-relevant surface climate variables (for each month of the year) using a two-box model fit to two 150-year/250-year greenhouse integrations with the Hadley Center AOGCM. The corresponding relative scaling patterns of regional changes were obtained by fitting the AOCGCM's (decade-averaged monthly) global mean time series to the individual time series in each land grid cell by variation of one scaling factor per grid cell. Thus the temporal and spatial signals represent one common parent model and calibration experiment.

In the following, we pursue the same basic pattern-projection strategy as Huntingford and Cox (2000), deriving both the spatial and temporal information simultaneously from the same transient AOGCM simulation. We then reproduce the (dimensionally reduced) space-time dependent AOGCM signal with an IRF model. To enhance the signal-to-noise ratio we separated the space-time dependent AOGCM output fields into noise and signal components using an EOF analysis applied to a long transient experiment ( 850 years) with the parent AOGCM, and restricted the analysis furthermore to annual means.

\subsection{Regional climate change signals}

To extract the climate change signal from the AOGCM response, consisting of a superposition of the externally forced signal and the natural variability of the AOGCM, we represent the response (forced scenario minus control run) as the superposition

$f^{v}(x, t)=\sum_{i} p_{i}^{v}(t) \cdot f_{i}^{v}(x)$

of a set of EOFs (empirical orthogonal functions) $f_{i}^{v}(x)$ with associated time-dependent scalar coefficients, the principal components (PCs) $p_{i}^{v}(t)$. The EOF decomposition maximizes the fraction of total variance explained at any given expansion order.

The time-evolution of the coefficients $p_{i}^{v}(t)$ for which the climate change signal can be clearly distinguished from the background natural climate variability (See Cubasch et al. 1992; Santer et al. 1994) can then be represented by an IRF model in the same way as the mean-temperature in the case of a singleindex CliC IRF model.

The EOF patterns and corresponding PCs used for our IRF model were extracted from an 850-year transient AOGCM simulation with the periodically synchronously coupled models ECHAM3 and LSG (Voss et al. 1998; Voss and Mikolajewicz 2000). The (equivalent) $\mathrm{CO}_{2}$ concentration was prescribed as exponential growth up to the fourfold 'preindustrial' level (330 ppm) at year 120 , after which the concentration was kept constant.

The analysis was carried out for the annual means of nearsurface temperature, precipitation, cloudiness, and sea level. The time series of the first six principal components for each of the four fields are shown in the four left panels of Fig. 6. The PCs of second and higher order show statistical fluctuations around zero, without a clear signal. However, the first PCs, $p_{1}^{v}(t)$, of all four variables start close to zero, but then clearly emerge from the noise during the course of the simulation. The signal growth closely follows the increase in the forcing during the first 120 years, but continues to increase after the forcing is kept constant, although on a slower time scale. The signal is best discernible in the sea level rise, but can be clearly distinguished from the noise also in the three atmospheric variables. Extrapolation of the $p_{1}^{S}(t)$ curve for sea level rise suggests that equilibrium would not be reached until well after a thousand years.

\subsection{Impulse-response representation}

Since the climate change signals of all four variables considered can be well captured by the first EOFs, while the higher EOFs are indistinguishable from the noise, the regional climate change signals can be reproduced by an IRF representation of just the first term in each of the expansions Eq. (2),

$f^{v}(x, t) \approx p_{1}^{v}(t) \cdot f_{1}^{v}(x)$

$p_{1}^{v}(t) \approx \frac{1}{\ln 2} \int_{t_{0}}^{t} R^{v}\left(t-t^{\prime}\right) \cdot \frac{\mathrm{d}}{\mathrm{d} t^{\prime}} \ln \left(\frac{w\left(t^{\prime}\right)}{w_{p}}\right) \cdot \mathrm{d} t^{\prime}$.

The assumed logarithmic relation between atmospheric carbon load $w$ and radiative forcing corresponds to the standard representation of the near-saturation of the principal $\mathrm{CO}_{2}$ infra-red absorption bands (IPCC 1990; Myhre et al. 1998). For concentrations below the reference value of $2 \times \mathrm{CO}_{2}$, the logarithmic expression yields a slightly warmer equilibrium than the linear model, while at higher concentrations the warming is significantly weaker. To fit the IRF function $R^{v}(t)$ to the AOGCM scenario simulation, the function was represented as a sum of exponentials:

$R^{v}(t)=S^{v} \sum_{i} a_{i}^{v}\left(1-\exp \left(\frac{-t}{\tau_{i}^{v}}\right)\right)$

where $\sum_{i} a_{i}=1$, so that $S^{v}$ represents the model's asymptotic climate sensitivity to a $\mathrm{CO}_{2}$ doubling.

The climate change signal patterns $f_{1}^{v}(x)$ were normalized to have unit global means (Figs. 2-5). Thus, the $p_{1}^{v}(t)$ time series represent global mean climate change signals, the patterns indicating where the change is larger $\left(f_{1}^{v}(x)>1\right)$ or smaller $\left(f_{1}^{v}(x)<1\right)$ than the global mean.

The time constants $\tau_{i}^{v}$ and amplitudes $a_{i}^{v}$ of $R^{v}$ were obtained by a least-squares fit of the IRF model to the $p_{1}^{v}$ time series (Table 2). Low signal-to-noise ratio did not permit determination of more than two time constants of the IRFs. Least-square fit experiments on a coarse $2 \mathrm{~d} \tau_{1}^{v}-\tau_{2}^{v}$ grid (with the $a_{i}^{v}$ optimized at each $\tau_{1}^{v}-\tau_{2}^{v}$ gridpoint) indicated that for the atmospheric variables (temperature, cloud cover, precipitation) the fit quality (rms) is relatively little changed within a range of appropriate combinations of the two time constants $\left(300-700\right.$ years for $\tau_{1}^{v}$ and $12-$ 28 years for $\tau_{2}^{v}$ ). However, for sea level the first time constant was well determined at $\tau_{1}^{v}=800$ years, with $\tau_{2}^{v}$ lying in the range 20 30 years. This can be explained by the different relative weightings of the short and long time scales for the atmospheric variables, for 
which the short-time relaxation terms dominate over the long-time terms by factors of $2-4$, compared with sea level, for which the short-term contribution is less than $4 \%$ of the long-term contribution.

Although cloud cover and precipitation are important variables for impact studies, their climate change signals exhibit lower signal-to-noise ratios than the near-surface temperature and are thus less reliably determined (Fig. 6, right panels). However, all three variables represent simultaneous expressions of the total atmospheric response and may therefore be expected to exhibit similar time response characteristics. The responses would be identical, for example, if the atmosphere responds quasi-instantaneously to changes in the sea surface temperature, sea-ice cover and land moisture distribution, and the dynamic response characteristics of these variables with "memory" can be represented by a single joint EOF pattern. We have accordingly tested the fit of a single IRF to all three variables, using the $t_{2 m}$ IRF model (which is most closely constrained by the data), appropriately scaled by the individual sensitivities $(-0.87 \%$ for clo and $0.15 \mathrm{~mm} / \mathrm{d}$ for pre). A good fit was achieved for both cloud coverage and precipitation, with rms errors only $3 \%$ greater than those of the independent best fits for each variable.

For greater numerical efficiency of the NICCS model, in which the CarC \& CliC IRF modules were coupled together, we also constructed for the CliC IRF an equivalent differential box-model analogue that could be directly coupled to the differential equivalent of the CarC IRF module. Both models could then be integrated within the same time-integration loop, avoiding also the second nested time-variable loop required for the standard integral formulation of the CliC IRF.
Fig. 2 Near-surface temperature change pattern $($ mean $=1)$

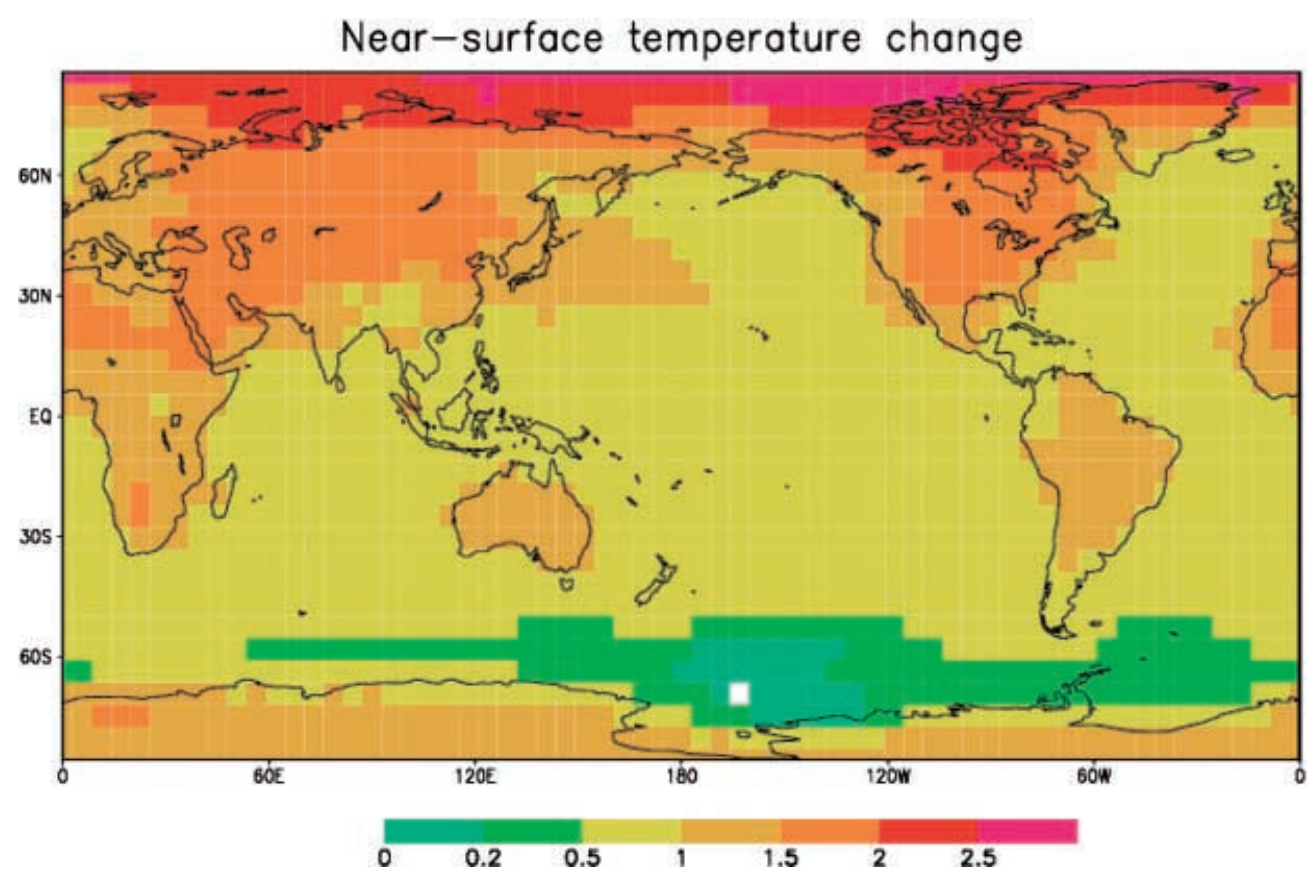

Fig. 3 Cloud cover change pattern. Note that positive values indicate decreasing coverage

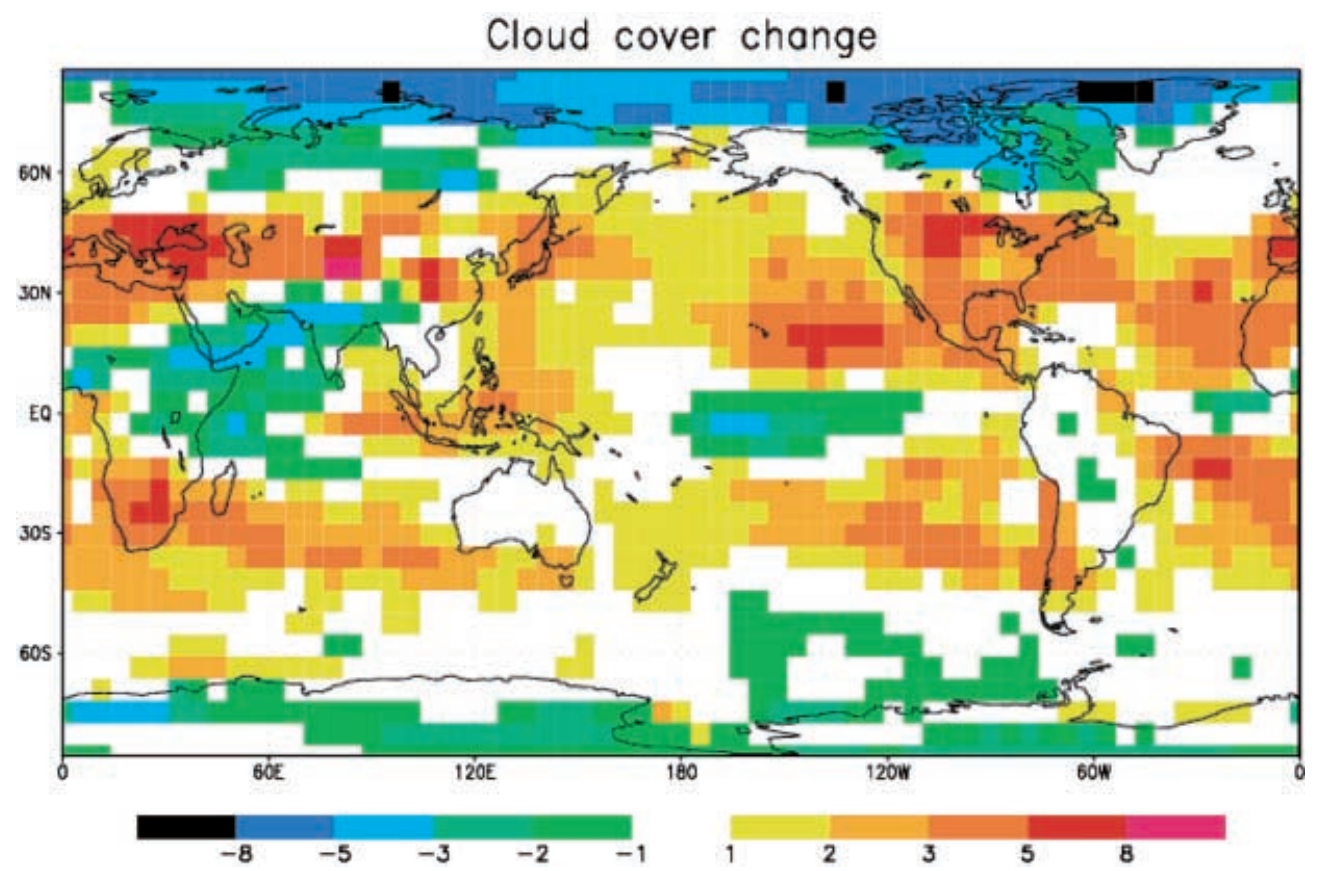


Fig. 4 Precipitation change pattern

Fig. 5 Sea level rise pattern
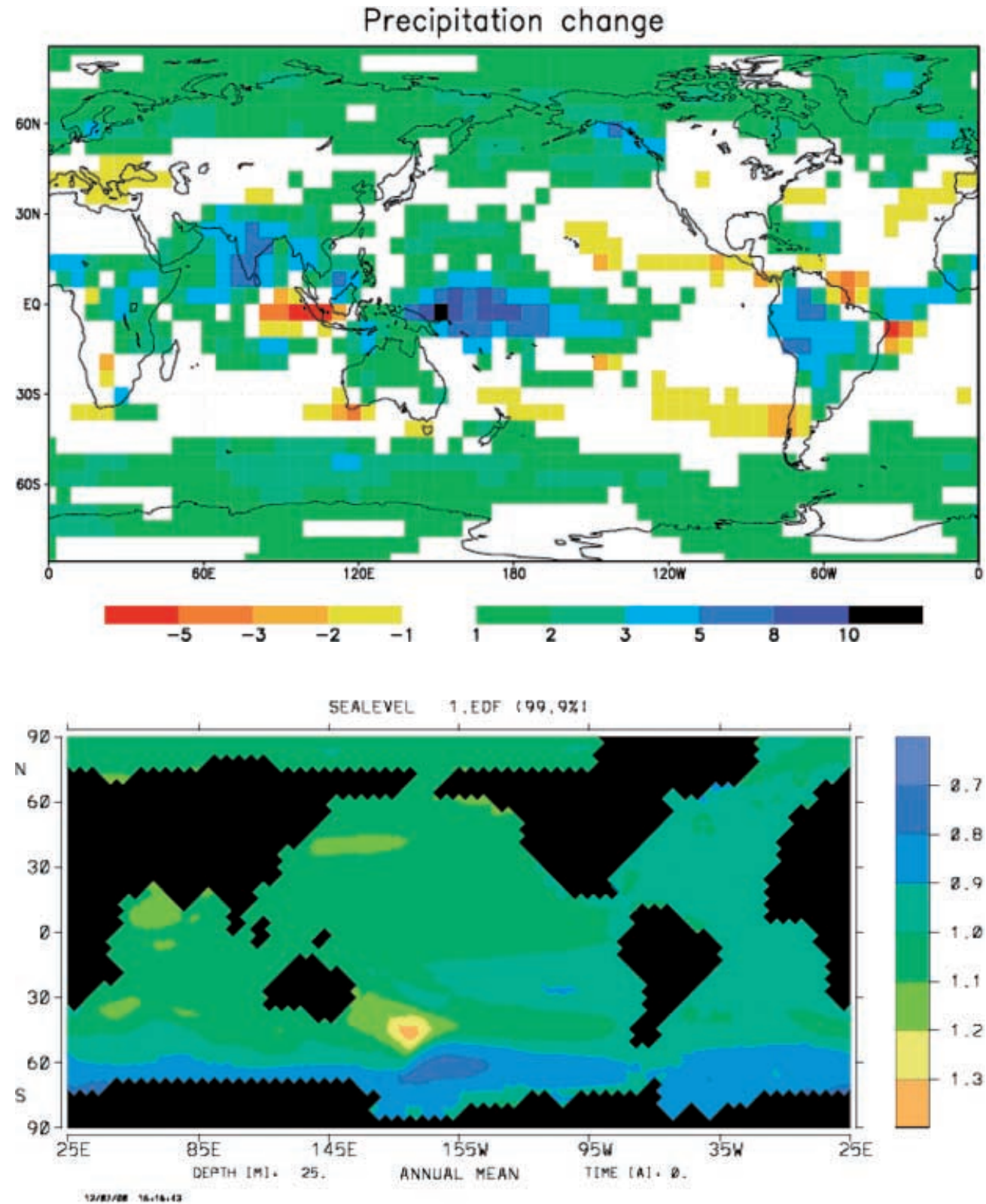

Table 2 Amplitudes, time constants, and climate sensitivities for the IRFs of global and annual mean near-surface temperature, cloud coverage, precipitation, and sea level, fitted to the transient ECHAM3-LSG 850-year $4 \times \mathrm{CO}_{2}$ experiment

\begin{tabular}{llllll}
\hline$v$ & $a_{1}^{v}$ & $\tau_{1}^{v}$ & $a_{2}^{v}$ & $\tau_{2}^{v}$ & \multicolumn{1}{l}{$S^{v}$} \\
\hline$t_{2 m}$ & 0.290 & 400.0 & 0.710 & 12.0 & $2.39{ }^{\circ} \mathrm{C}$ \\
clo & 0.212 & 400.0 & 0.788 & 12.0 & $-0.837 \%$ \\
pre & 0.305 & 400.0 & 0.695 & 28.0 & $0.146 \mathrm{~mm} / \mathrm{d}$ \\
sea & 0.963 & 800.0 & 0.037 & 25.0 & $1.137 \mathrm{~m}$
\end{tabular}

We point out in conclusion that the limitation to the onedimensional representation of annual mean values of four selected variables is not dictated a priori by the model design. The approach may be readily generalized to higher-order EOFs, if these can be reliably distinguished from noise through sufficiently long integrations or Monte Carlo simulations, and it can be applied to any variable that is (directly or indirectly) provided by the parent AOGCM, such as seasonal variability or higher-moment statistics. The system's response to forcing mechanisms other than greenhouse gases, like sulfate or volcanic aerosols, or solar variability, can be similarly treated in terms of further linearly superimposable IRF models.

\section{Experiments}

4.1 Nonlinear impulse response of the coupled carbon cycle-climate system

To illustrate the main dynamical features of our nonlinear IRF model, we computed the response of three variants of the model to three different $\delta$-function $\mathrm{CO}_{2}$-emission inputs, representing a sudden increase of the pre-industrial atmospheric $\mathrm{CO}_{2}$ concentra- 
Fig. 6a-d Left, from above: principal component analysis of the changes (scenario minus control) in a 2 m-temperature, b cloud coverage, $\mathbf{c}$ precipitation, and $\mathbf{d}$ sea level, in the transient $4 \times \mathrm{CO}_{2}, 850$-year simulation with the ECHAM3-

LSG AOGCM. Shown are time series of the leading six principal components $p_{1}^{v}, \ldots, p_{6}^{v}$. Right: fit of IRF models to the $p_{1}^{v}$ time series. Sign reversals are due to renormalization, for convenience, to unit global pattern mean and global-mean time series. Also shown for cloud coverage and precipitation changes are the appropriately rescaled temperature response curves (dashed)
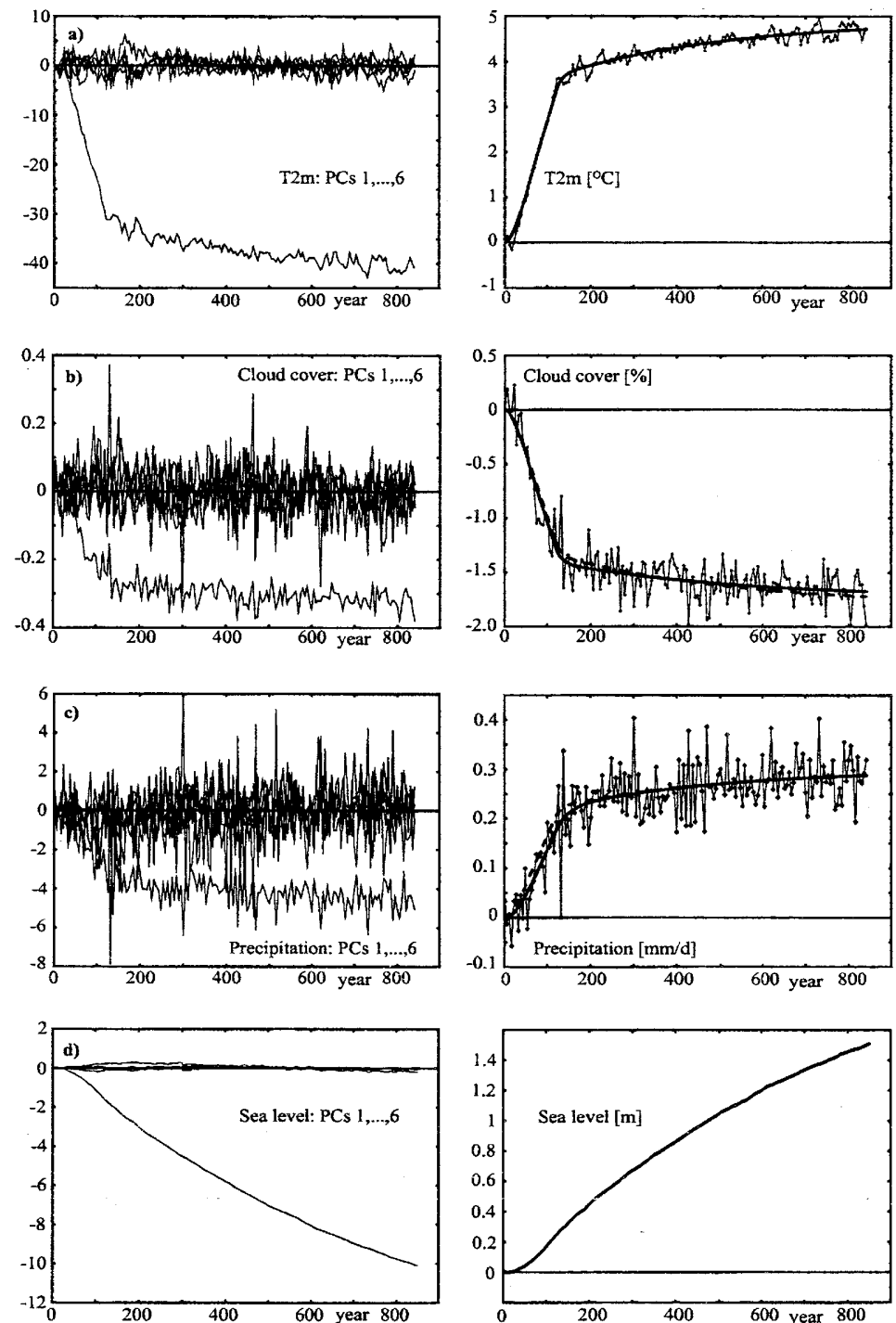

tion by factors of 1.25, 2 and 4, respectively (Fig. 7). For comparison, we also ran the parent ocean carbon cycle model for these cases (Fig. 1). The IRF model variants were:

1. The linear ocean carbon uptake module combined with linear radiative forcing (the linear convolution, or LC variant, as used in the impulse-response climate module of Hasselmann et al. (1997, dot-dashed lines in Fig. 7).

2. The nonlinear ocean IRF analogue together with the logarithmic radiation model (the NO variant, solid lines);

3. The same as the NO variant, but with the nonlinear ocean carbon cycle augmented by a simple $\mathrm{CO}_{2}$-fertilized terrestrial biosphere carbon pool, adapted from Joos et al. (1996) (the BJ variant, dashed lines).

The weakest $\mathrm{CO}_{2}$ input, representing an increase of the initial atmospheric $\mathrm{CO}_{2}$ concentration by $25 \%$, or $\approx 140 \mathrm{GtC}$, relative to the pre-industrial level, corresponds to the total accumulated anthropogenic emissions from early industrialization until the 1980s. The response of the ocean carbon cycle (NO) is still close to the linear case (LC). Inclusion of the land biosphere pool (BJ) leads to a faster decay initially, which slows down later, however, when the additional sequestered biospheric carbon starts returning to the atmosphere. The small asymptotic biospheric retention is determined by the equilibrium between the slightly increased NPP and the respirative decay of the additional carbon.
The temperature responses of all three model variants exhibit a relatively rapid adjustment to the sudden $\mathrm{CO}_{2}$ increase initially, with time scales governed by the heat uptake of the ocean, mainly in the upper $1 \mathrm{~km}$. This is followed by a slow temperature decrease mirroring the decay of the $\mathrm{CO}_{2}$ concentration. The nonlinear model yields substantially larger temperature changes than the linear model, as the $\mathrm{CO}_{2}$ concentrations remain well below the $2 \times$ preindustrial level, the break-even point at which the linear and logarithmic greenhouse forcing are the same. The enhanced logarithmic forcing relative to the linear forcing in this low-concentration range overcompensates the concentration drawdown by the land biosphere carbon pool.

The response in sea level is dominated by the extremely slow warming of the deep ocean. Thus the fast initial temperature response to the sudden $\mathrm{CO}_{2}$ increase, which was governed mainly by the heat uptake in the main thermocline of the ocean, does not appear as a significant signal in the sea level response. This is characterized rather by the long time scales describing the gradual relaxation of the $\mathrm{CO}_{2}$ concentration to its equilibrium asymptotic value, both processes being determined by the rate of penetration of tracers $\left(\mathrm{CO}_{2}\right.$ and heat) into the deep ocean.

The intermediate impulse, representing an initial doubling of the $\mathrm{CO}_{2}$ concentration relative to the preindustrial state, corresponds to the estimated accumulated emissions $(560 \mathrm{GtC})$ for a typical business-as-usual emissions scenario some time near the 
Fig. 7 Nonlinear response of the coupled carbon cycleclimate model (NICCS) to sudden increases of the preindustrial atmospheric $\mathrm{CO}_{2}$ concentration by $25 \%$, (left), $100 \%$ (center), and $300 \%$ (right). From top: atmospheric $\mathrm{CO}_{2}$ perturbation, global-mean near-surface air temperature change $\left({ }^{\circ} \mathrm{C}\right)$, and global-mean sea level change (m). Each panel shows the response of three IRF model variants: the nonlinear ocean $\mathrm{CO}_{2}$ model without (NO, solid lines) and with land biosphere (NB, dashed), in both cases coupled to the logarithmic greenhouse forcing climate module, and the coupled linear convolution models of oceanic $\mathrm{CO}_{2}$ uptake and climate change (LC, dot-dashed)
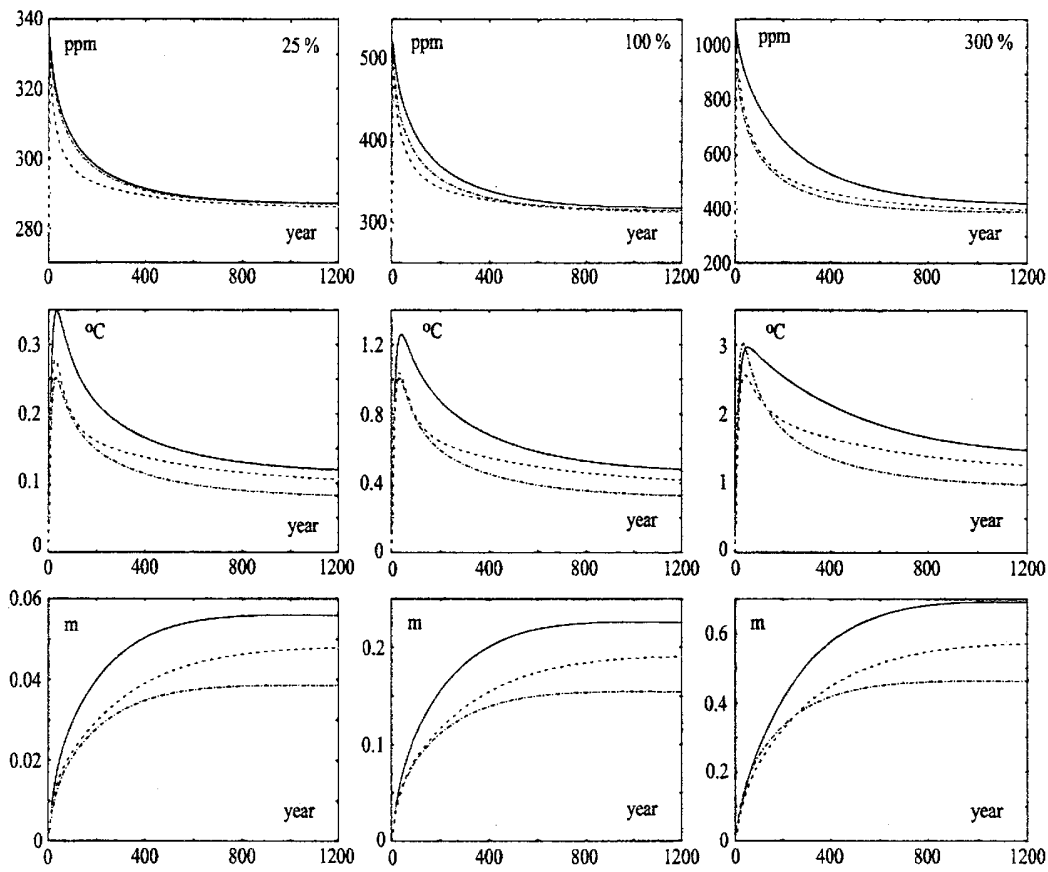

middle of this century. Although the oceanic uptake is already somewhat slower than in the first experiment with weaker input, the overall climate response is not drastically changed. The difference between the linear and logarithmic greenhouse modules has become smaller, thereby reducing the greenhouse forcing relative to the linear case and partially compensating the effect of the relatively higher $\mathrm{CO}_{2}$ concentrations resulting from the slower nonlinear carbon uptake.

In contrast, the largest $\mathrm{CO}_{2}$ impulse, corresponding to a sudden $\mathrm{CO}_{2}$ quadrupling (1650 $\mathrm{GtC}$ input), is sufficiently large to drive the oceanic carbon uptake well out of its linear regime, although even this input is still substantially smaller than estimates of the total fossil fuel resources, including anticipated but not yet discovered resources, of 4000 to more than $25000 \mathrm{GtC}$, See IPCC (1996, 2000). As the peak temperature response of $3{ }^{\circ} \mathrm{C}$ is now above the breakeven point of the logarithmic radiative forcing, the nonlinear variant yields a weaker forcing than the linear variant. The effect is sufficiently strong to over-compensate the higher $\mathrm{CO}_{2}$ concentrations of the nonlinear ocean uptake model, so that the peak warming is slightly lower than in the linear variant. Both the peak warming and the subsequent decay of the $\mathrm{CO}_{2}$ concentration are retarded relative to the linear case. The impact of the nonlinearities is least pronounced in all three model variants in sea level, where the largest impulse produces only a weak retardation relative to the linear case.

\subsection{Long-term emission scenarios}

Typical scenarios of climate change are computed over time horizons of 100 years (IPCC 1992, 2000; Nakicenović et al. 1998). It has been pointed out by several authors, in particular Cline (1992) (see also Hasselmann et al. 1997) that this time span is too short to cover the full range of the climatic consequences of today's policies, leading to dangerous underestimates of long-term climate change impacts. For many of the scenarios currently under discussion, the emissions have not ceased growing by the end of the 21 st century, and even after the emissions begin to fall, the cumulative $\mathrm{CO}_{2}$ input continues to rise. Because of the long residence time of $\mathrm{CO}_{2}$ in the atmosphere, it is the cumulative emissions rather than the instantaneous emissions that govern climate change. The slow uptake of the $\mathrm{CO}_{2}$ input by the oceans and the terrestrial biosphere and the large heat capacity of the ocean together produce an exceedingly long memory of the climate system extending over many centuries (See Fig. 7).

This is further illustrated in Figs. 8 and 9, which show the $\mathrm{CO}_{2}$ concentrations and climate change computed with the three IRF model variants described above, together with the $\mathrm{CO}_{2}$ concentrations computed with the ocean carbon cycle parent model, for two representative 1000 -year emission scenarios. The first case corresponds to a long-range 'Business as Usual' (BAU) scenario in which essentially all estimated fossil fuel resources are burnt in the course of a few centuries. The scenario corresponds to typical BAU scenarios (see IPCC 1996) for the twenty first century, while over the entire time horizon, the total cumulated BAU emissions amount to $15000 \mathrm{GtC}$, which lies in the middle range of estimates of total fossil resources (see above). In the second 'Frozen Emissions' (FRE) scenario, the emissions are kept constant at the 1990 level of $5.5 \mathrm{GtC} /$ year. The FRE scenario is representative of the cumulative emissions of typical "drastic-reduction scenarios" (see IPCC 1996) for the period up to 2100.

In both scenarios, the largest changes in atmospheric $\mathrm{CO}_{2}$ and climate occur well after the year 2100 , with a millenium-time-scale decay of the climate signal even after the emissions have faded out. For the BAU scenario, the $\mathrm{CO}_{2}$ concentrations reach extremely high values, between ten and twenty times higher than the preindustrial level, for which direct physiological damages to living organisms must be expected. The associated temperature changes are of the order of $10^{\circ} \mathrm{C}$. However, even the FRE scenario yields temperature changes of the order of $5{ }^{\circ} \mathrm{C}$ in the long term, of the same order as the warming since the last ice-age. Climate changes of this magnitude lie, of course, well outside the linear regime, in a range in which all climate models, including the parent models against which NICCS was calibrated, are no longer reliable. Thus, the computations should be interpreted only as an indication and warning of the major, basically unpredictable climate changes that can be anticipated if business-as-usual or insufficiently restrictive climate policies are pursued over long periods.

The linear ocean carbon cycle IRF model (LC) severely underestimates the $\mathrm{CO}_{2}$ concentrations predicted by the parent model (HAMOCC3i) for the BAU scenario. The concentrations are reduced by $25 \%$ already before the year 2100 , while the peak concentration is reached two centuries too early and is too small by a factor of three. In contrast, the atmospheric $\mathrm{CO}_{2}$ concentration computed with the nonlinear ocean carbon IRF module (NO) agrees with the parent model to within $10 \%$ during the entire 

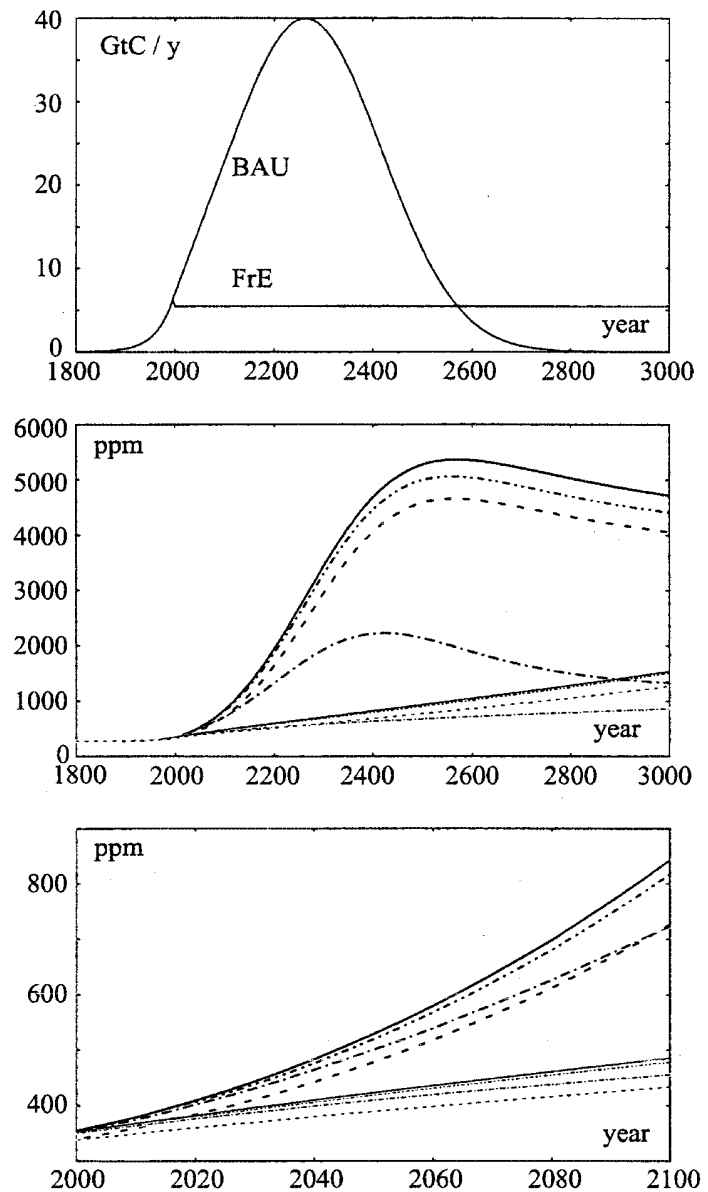

Fig. 8 'Business-as-usual' (BAU) and 'frozen emissions' (FRE) $\mathrm{CO}_{2}$ emission scenarios (upper panel) and resulting $\mathrm{CO}_{2}$ concentrations computed over the same 1000-year integration period (middle panel) and for the next 100 years (lower panel). Computations were made with three IRF model variants: the nonlinear ocean $\mathrm{CO}_{2}$ model without (NO, solid lines) and with land biosphere (NB, dashed) and with the linear convolution model (LC, dot-dashed), and also with the parent 3D ocean carbon cycle model HAMOCC3i (dot-dot-dashed)

1000-year BAU period, including even the extreme peak value of $5000 \mathrm{ppm}$. Note that in all runs the initial state was defined as the preindustrial state in the year 1800 , so that the different model variants yield different $\mathrm{CO}_{2}$ concentrations and climate states already today. This is most visible in the run with the land biosphere module.

Driving the ocean-chemistry module at a strongly reduced temperature (Northern Atlantic winter instead of global mean temperature) did not modify the results significantly, while inclusion of the land biosphere module (BJ) shifted the concentrations down by about $15 \%$ in both scenarios. However, the terrestrial biosphere could have a stronger impact if the feedbacks through changes in temperature and water availability are included. In the BAU scenario, the impact of the terrestrial carbon sink on climate is particularly weak, since the logarithmic radiative forcing is insensitive to relative changes in $\mathrm{CO}_{2}$ concentrations at large background concentrations. In the FRE climate response, the combined nonlinearities of ocean chemistry, land vegetation, and radiation happen to very nearly cancel.

In general, the net climate response of the IRF module was found to be rather robust with respect to details of the carbon cycle module, for example with regard to the direct temperature effect on ocean chemistry, the capacity of the terrestrial pool or modification of the terrestrial biosphere through changes in climate. Although
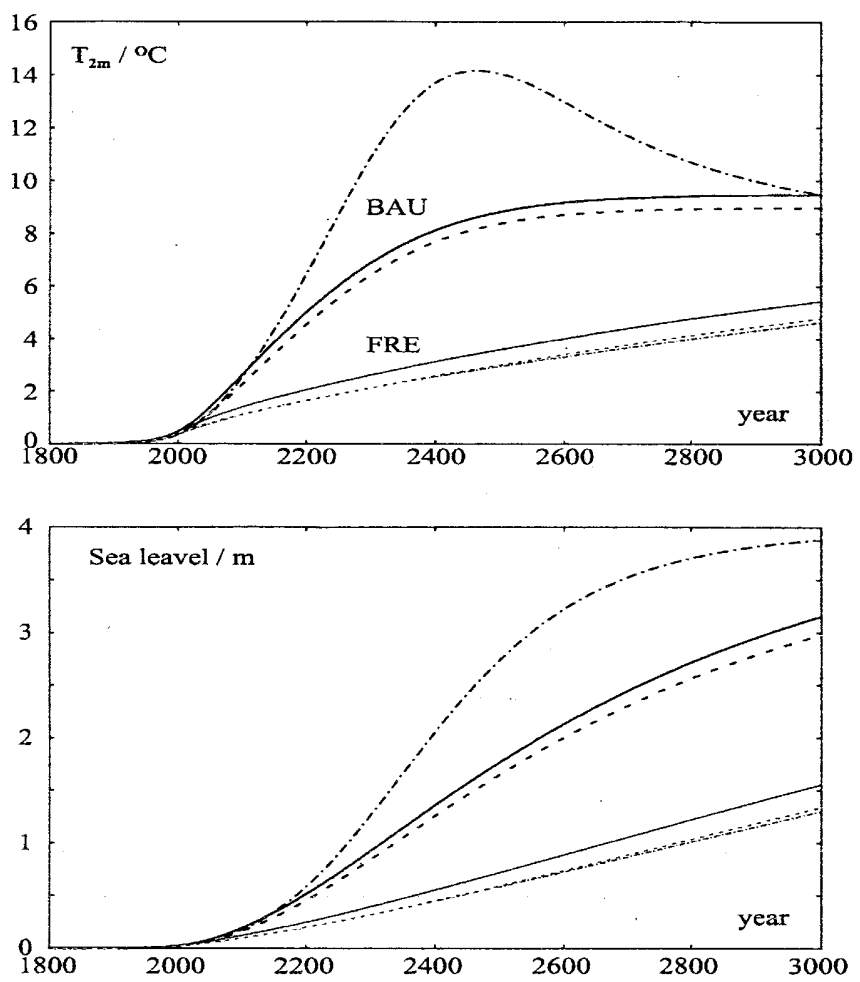

Fig. 9 Annual-global-mean climate change for scenarios $B A U$ und $F R E$ computed using three IRF model variants: the nonlinear ocean $\mathrm{CO}_{2}$ model without (NO, solid lines) and with land biosphere (NB, dashed), in both cases coupled to the logarithmic greenhouse forcing climate module, and the coupled linear convolution models of oceanic $\mathrm{CO}_{2}$ uptake and climate change (LC, dot-dashed)

the $\mathrm{CO}_{2}$ concentrations become more uncertain at higher levels, this is compensated in part by the decreased sensitivity of the climate response to changes in the $\mathrm{CO}_{2}$ concentration as the $\mathrm{CO}_{2}$ infrared absorption bands become more saturated.

A comparison of the changes in global mean temperature, as proxy for the atmospheric variables, with sea level (Fig. 9) shows that sea level responds much more slowly than the atmospheric variables, as found already in the impulse experiments. Since the dominant time scale of the sea level response ( 800 years) is large compared even with the multi-century growth time of the BAU concentrations, the sea level response for this scenario is similar to the response to a step-function increase in $\mathrm{CO}_{2}$ concentration discussed earlier. The sea-level rise for the FRE scenario is approximately linear over the entire period.

In further experiments, the optimal emission-path computations of Hasselmann et al. (1997) were repeated using NICCS rather than the linear IRF model SIAM. As expected, the costbenefit analyses of Hasselmann et al. (1997) were found to be robust with respect to the relatively small nonlinear modifications of the climate response in the range of modest climate change (normally less than $3{ }^{\circ} \mathrm{C}$ warming) occurring in the optimal emission solutions.

\section{Summary}

Integrated assessment of anthropogenic climate change requires cost-efficient models of the carbon cycle and the atmosphere-ocean climate system that approach nevertheless the reliability and credibility of complex, stateof-the-art 3D carbon cycle and general circulation 
models. As a convenient tool for this purpose, we have developed nonlinear impulse-response-function (IRF) representations of the response characteristics of the HAmburg Model of the Ocean Carbon Cycle (HAMMOC3i) and the Hamburg coupled atmosphere-ocean general circulation model ECHAM3-LSG. Coupled together, the net IRF model NICCS (nonlinear impulse response model of the coupled carbon cycle-climate system) computes the atmospheric $\mathrm{CO}_{2}$ concentration and the resulting changes in selected impact-relevant climate fields (near-surface temperature, cloud cover, precipitation and sea level) for a prescribed 1000 year $\mathrm{CO}_{2}$ emission scenario within less than a second on a workstation. NICCS is thus a valuable instrument for providing for the integrated assessment community the detailed output information of state-of-the-art climate models without loss of reliability for modest climate change at greatly reduced computational cost.

The limitation of IRF models to modest perturbations (below $\mathrm{CO}_{2}$ doubling and $3{ }^{\circ} \mathrm{C}$ warming) for which the climate response can be approximately linearized was partially overcome in NICCS by explicit treatment of two dominant nonlinearities: the nonlinear inorganic carbon chemistry governing the $\mathrm{CO}_{2}$ uptake in the ocean, and the logarithmic dependence of the radiative greenhouse forcing on the $\mathrm{CO}_{2}$ concentration. This was augmented by a land vegetation carbon cycle module with a nonlinear formulation of net primary production. Although inclusion of these nonlinearities removes the more obvious shortcomings of linear response models, it must be stressed that many more nonlinearities arise in the real climate system (and state-of-the-art climate models) at higher climate-change amplitudes, and these can not be adequately reproduced in an IRF model. The lowest-order extension of a linear IRF model to a general quadratic response model, for example, requires already the calibration of a set of three-index response coefficients rather than the set of standard two-index response matrices of a linear IRF model. Thus the introduction of just two dominant nonlinearites into the NICCS model should be regarded only as a stop-gap measure to obtain more realistic order-of-magnitude estimates of amplitudes, without claims to a realistic description of the nonlinear modifications of the climate-change response patterns.

Another shortcoming of NICCS is that it neglects feedbacks of greenhouse warming on the ocean carbon cycle resulting from changes in the ocean circulation, since the ocean carbon cycle IRF was calibrated against a 3D carbon cycle model with a prescribed ocean circulation field. This shortcoming can be overcome by calibrating both modules of a coupled IRF model against a coupled model of the carbon cycle and the general atmosphere-ocean circulation system. However, previous studies with 3D ocean carbon cycle models (Maier-Reimer et al. 1996; Sarmiento et al. 1998) indicate that the feedbacks of global warming on downwelling transport, vertical mixing, solubility and the biological pump partly compensate each other for atmospheric $\mathrm{CO}_{2}$ concentrations up to about $700 \mathrm{ppm}$, leaving only a small residual effect of global warming on the oceanic $\mathrm{CO}_{2}$ uptake. Maier-Reimer et al. (1996) conclude that 'the currently used modelling strategy of first using a carbon cycle model for the transformation of anthropogenic emissions into $p \mathrm{CO}_{2}$ and subsequently using the output as forcing for a physical climate model, appears justified'. We have accordingly run NICCS in the sequential, decoupled mode, without consideration of global warming feedbacks on the carbon cycle.

At atmospheric $\mathrm{CO}_{2}$ concentrations exceding $700 \mathrm{ppm}, 3 \mathrm{D}$ ocean carbon cycle models indicate that the reduced ocean circulation and other climate feedbacks tend to slow down the $\mathrm{CO}_{2}$ ocean uptake, so that NICCS probably underestimates the atmospheric $\mathrm{CO}_{2}$ concentration in the high-emission scenarios. Fortunately, however, the uncertainties of high $\mathrm{CO}_{2}$ concentrations map into smaller climate change uncertainties through the logarithmic dependence of the radiative forcing on the $\mathrm{CO}_{2}$ concentration.

Another limitation of present IRF models is that they are unable to simulate an unstable transition of the climate system to a new state, such as a breakdown of the ocean thermohaline circulation, a destabilization of the West Antarctic ice shield, a run-away greenhouse effect triggered by the release of methane trapped in permafrost regions, or a large-scale disruption of terrestrial ecosysems. The various nonlinear, physical-biogeochemical processes involved in surprises of this kind are not yet well understood. They cannot be reliably simulated or predicted today, even with the most sophisticated climate models. Thus, there exist at present no suitable parent models against which an appropriately extended nonlinear IRF model could be calibrated.

Conceptually, many of these shortcomings can probably be overcome by a suitable generalization of the basic NICCS structure, once the governing processes are understood and the relevant sophisticated parent models needed for calibration have been developed. However, an important generalization of the present NICCS which is feasible already today is the inclusion of further climate change variables provided by the parent model, such as annual and diurnal cycles, the occurrence of extreme events and, generally, changes in the statistics of the internal spatiotemporal variability of the climate system. It is in these properties that the impact of future climate change will probably be felt most strongly.

Our examples of the application of NICCS to longterm $\mathrm{CO}_{2}$ emission scenarios demonstrated that the estimated total fossil-fuel resources are more than sufficient to carry the climate system into a range of extreme $\mathrm{CO}_{2}$ concentrations and temperature increases far in excess of the bounds within which any climate model can presently provide reliable predictions. Even a freezing of $\mathrm{CO}_{2}$ emissions at 1990 levels is unable to stabilize the $\mathrm{CO}_{2}$ concentration and limit global warming to acceptable levels in the long term. However, the long memory of the climate system provides also an opportunity for the gradual transition to carbon-free energy technologies 
over several decades, without dislocations of the global economy (see Hasselmann et al. 1997). A repeat of the optimal emission path computations of Hasselmann et al. (1997), in which the linear climate module of their coupled climate-socioeconomic model SIAM was replaced by NICCS, confirmed the robustness of the conclusions of these authors with respect to model details. NICCS has been used and is currently being applied in integrated assessment studies (Bruckner et al. 1999; Petschel-Held et al. 1999; Füssel and van Minnen 2000) in investigations of climate change feedbacks onto the terrestrial carbon cycle (Joos et al. 1999; Meyer et al. 1999), and as an educational tool developed for the EXPO2000 World Exhibition. It is available as a community model on the Internet.

\section{Appendix: The ocean carbon cycle module}

\section{A.1 The linear impulse response function of the composite-layer}

A good fit to the linear atmospheric response $\hat{R}_{c}(t)$ of the $3 \mathrm{D}$ ocean carbon cycle model of Maier-Reimer and Hasselmann (1987) to atmospheric $\mathrm{CO}_{2}$ input can be obtained by a sum of four decaying exponentials plus a constant defining the asymptotic equilibrium state:

$\hat{R}_{c}(t)=\sum_{i=0}^{4} A_{i} \exp \left(\frac{-t}{\tau_{i}}\right)$

with $\tau_{0}=\infty$

and $\sum_{i} A_{i}=1$.

The shortest decay time $\tau_{4}$ can be interpreted as the compositelayer equilibration time, the associated amplitude $A_{4}$ representing the fraction of a given $\delta$-impulse carbon input into the atmosphere at time $t=0$ which becomes dissolved in the ocean surface layer within the time scale $\tau_{4}$. The ratio of the impulse-added $\mathrm{CO}_{2}$ content of the composite layer to the change of the atmospheric $\mathrm{CO}_{2}$ content shortly after equilibration is accordingly $1 /\left(1-A_{4}\right)$. The linearized impulse response of the composite layer can thus be obtained from the IRF representation of the atmospheric response of the complete model of Maier-Reimer and Hasselmann (1987) by dropping the short-time scale term and subsequently renormalizing:

$R_{c}(t)=\sum_{i=0}^{3} a_{i} \exp \left(\frac{-t}{\tau_{i}}\right)$

with $\tau_{0}=\infty$

and $\quad a_{i}=\frac{A_{i}}{1-A_{4}}$

\section{A.2 The equivalent differential analogue}

The IRF model Eqs. (9)-(11) is replaced in NICCS by a numerically equivalent differential model representing a cascade of layers $i$ of carbon content $c_{i}$ which are coupled through Newtonian fluxes between neighbouring layers proportional to the concentration differences. The flux into the uppermost (composite) layer $i=0$ is given by the (prescribed) anthropogenic emissions: $q_{0}=e(t)$. Thus the differential system has the form

$\dot{\boldsymbol{c}}+\mathbf{D} \boldsymbol{c}=\boldsymbol{e}$ where $\boldsymbol{c}(t)=\left(c_{0}, \ldots, c_{n-1}\right), \boldsymbol{e}(t)=(e(t), 0, \ldots, 0)$ and $\mathbf{D}$ represents the Newtonian transfer matrix. For the case of $n=4$ relaxation times $\tau_{i}$, as in Eq. (9), the transfer matrix is given by

$\mathbf{D}=\left(\begin{array}{cccc}\frac{\eta_{1}}{h_{0}} & -\frac{\eta_{1}}{h_{1}} & 0 & 0 \\ -\frac{\eta_{1}}{h_{0}} & \frac{\eta_{1}+\eta_{2}}{h_{1}} & -\frac{\eta_{2}}{h_{2}} & 0 \\ 0 & -\frac{\eta_{2}}{h_{1}} & \frac{\eta_{2}+\eta_{3}}{h_{2}} & -\frac{\eta_{3}}{h_{3}} \\ 0 & 0 & -\frac{\eta_{3}}{h_{2}} & \frac{\eta_{3}}{h_{3}}\end{array}\right)$.

The Newtonian transfer coefficients $\eta_{i}(i=1, \ldots, n-1)$ and the layer thicknesses $h_{i}(i=0, \ldots, n-1)$ are tunable constants. Unfortunately, the relations between the parameters $h_{i}, \eta_{i}$ of the differential analogue and the the parameters $a_{k}, \tau_{k}$ of the composite-layer IRF $R_{c}$ are nonlinear and cannot be derived in closed form. They must be determined by satisfying a set of tuning conditions derived from the analytical Green function solution of the linear model equations.

\section{A.3 Tuning the differential analogue}

To tune the parameters of the differential analogue model to the parameters of the linear IRF model, we first diagonalize $\mathbf{D}$ by expressing both the solution $c_{i}(t)$ and the forcing $e_{i}(t)$ in terms of the eigenvectors of $\mathbf{D}$ :

$c_{i}(t)=\sum_{k} x_{k}(t) C_{i k}$

$e_{i}(t)=\sum_{k} r_{k}(t) C_{i k}$

where $C_{i k}$ is the $i$ th-layer component of the eigenvector $\mathbf{C}_{k}$ of $\mathbf{D}$ associated with the eigenvalue $\lambda_{k}$ (for the Newtonian relaxation system described by Eqs. $(12,13)$, the $\lambda_{k}$ are real and positive):

$\sum_{j} D_{i j} C_{j k}=\lambda_{k} C_{i k}$

Comparison of the zeroth-layer solution for the case of a $\delta$-impulse forcing $\left(e(t)=c^{\delta} \delta(t), r_{k}(t)=r_{k}^{\delta} \delta(t)\right.$, with constant $\left.c^{\delta}, r_{k}^{\delta}\right)$, with the composite-layer impulse response function (9) yields the tuning conditions

$\lambda_{k}=\tau_{k}^{-1}$

$\frac{r_{k}^{\delta} C_{0 k}}{c^{\delta}}=a_{k} \quad(k=0, \ldots, n-1)$.

The condition $\lambda_{0}=\tau_{0}^{-1}=0$ is satisfied through the conservation of carbon by the analogue model, which requires $\sum_{j} D_{i j}=0$ and therefore a singular propagator, $|\mathbf{D}|=0$.

The eigenvectors $\mathbf{C}_{k}$ and eigenvalues $\lambda_{k}$, and thereby also the forcing representation in eigenvector coordinates $r_{k}^{\delta}$, depend on the layer thicknesses $h_{i}(i=0, \ldots, n-1)$ and diffusion coefficients $\eta_{i}(i=1, \ldots, n-1)$. These must be determined numerically such that the conditions (17) and (18) are fulfilled.

With given $\tau_{0}=\infty$ and the renormalization condition $\sum_{i} a_{i}=1$, the composite-layer IRF Eq. (9) has six remaining independent parameters. For $n=4$, the analogue clearly contains the required four time constants (one of which is infinite). However, it contains seven rather than six free tuning parameters (four layer thicknesses $h_{i}$ and three diffusion constants $\eta_{i}$ ). The additional degree of freedom arises because the analogue model computes only the carbon content of the layers, not their concentrations. Thus the model is determined through $R_{c}$ only up to an arbitrary scaling factor: the transport matrix $\mathbf{D}$ is homogeneous in the ratios $\eta / h$, and the thicknesses of all layers can be changed by an arbitrary factor, provided the carbon exchange coefficients are changed by the same factor.

The additional degree of freedom can be fixed by the known relation between the carbon content and $\mathrm{CO}_{2}$ concentration of the atmosphere. Applying the known linear-limit ratio of the $\mathrm{CO}_{2}$ concentrations in the two subsystems atmosphere, mixed layer of 
the composite layer, one obtains for the layer thicknesses of the mixed-layer and composite-layer (expressed in equivalent water units), after some algebra:

$h_{s}=\frac{\xi_{p} w_{p}}{A_{o c} m_{C} \Sigma C_{p}} \cdot \frac{A_{4}}{1-A_{4}}$,

$h_{0}=\frac{\xi_{p} w_{p}}{A_{o c} m_{C} \Sigma C_{p}} \cdot \frac{1}{1-A_{4}}$,

where $\xi$ is the preindustrial Revelle buffer factor (see later), $w_{p}$ the preindustrial atmospheric carbon content, $m_{C}$ the molar mass of carbon, and $A_{o c}$ the area of the world ocean.

\section{A.4 Introduction of nonlinear chemistry}

The differential cascade analogue to the IRF model has been introduced primarily as a mathematical tool to reproduce the response of the more sophisticated carbon-cycle model to anthropogenic forcing via the tuning to an intermediate IRF model, without reference to real physical processes or observations. However, we ascribe now a specific physical interpretation to the composite layer of the differential analogue by regarding it as composed explicitly of the atmosphere and the mixed layer. Although we have used this terminology already in the analysis, the physical interpretation has had no mathematical implications so far apart from determining the free scaling parameter of the analogue model (which is irrelevant as long as we consider only the net carbon content of the composite layer, without attaching a physical significance to the layer). By interpreting the composite layer physically, we may now extend the linear IRF model into the nonlinear domain by considering the nonlinear chemical equilibration between the atmosphere and the mixed layer.

While the Newtonian flux $q_{1}$ from the zeroth (composite) layer into the first oceanic layer is still linear at large partial pressures of $\mathrm{CO}_{2}$, the surface-layer carbon content anomaly $c_{s}$ becomes a nonlinear function of the composite-layer carbon content anomaly $c_{0}$. The function $c_{s}=c_{s}\left(c_{0}\right)$ can be computed from the nonlinear chemistry of the mixed layer, given the thicknesses of the mixed-layer and the atmosphere and the equilibrium ratios of the partial pressures of $\mathrm{CO}_{2}$ in the atmospheric and ocean. Thus, the expression $c_{0} / h_{0}$ in the analogue's dynamical Eqs. $(12,13)$ is no longer equal to the surface layer concentration. However, the thicknesses of the composite layer and its subsystems are chosen to ensure this is the case in the linear limit:

$\lim _{c_{0} \rightarrow 0}\left(\frac{c_{s}}{h_{s}}\right)=\frac{c_{0}}{h_{0}}$.

The evolution Eq. (13) therefore need to be reformulated for the two uppermost layers in terms of the explicit nonlinear relation $c_{s}\left(c_{0}\right)$ :

$\dot{c}_{0}=e(t)-\frac{\eta_{1}}{h_{s}} c_{s}\left(c_{0}\right)+\frac{\eta_{1}}{h_{1}} c_{1}$

$\dot{c}_{1}=\frac{\eta_{1}}{h_{s}} c_{s}\left(c_{0}\right)-\frac{\eta_{1}+\eta_{2}}{h_{1}} c_{1}+\frac{\eta_{2}}{h_{2}} c_{2}$

The linear Eq. (12) and (13) for $\dot{c}_{2}$ and $\dot{c}_{3}$ remain unchanged.

For the numerical integration of the nonlinear analogue, the nonlinear relation $c_{s}\left(c_{0}\right)$ is evaluated at each time step by computing the chemical equilibrium determined by the various chemical processes associated with the dissolution and dissociation of $\mathrm{CO}_{2}$ in seawater.

Solving the system for several slightly perturbed values of $p \mathrm{CO}_{2}$ relative to its preindustrial value $p \mathrm{CO}_{2, p}$ yields a finite-difference estimate of the preindustrial buffer factor $\xi_{p}$. With consistent values of $p \mathrm{CO}_{2, p}, \Sigma C_{p}$, and $\xi_{p}$, the thickness of the composite layer, $h_{0}$, (and thereby its volume, given the total surface area $A_{o c}$ of the world ocean) can be computed from Eq. (19). The carbon content anomaly in the mixed layer, $c_{s}$, can then be found numerically for any given carbon content anomaly in the composite layer, $c_{0}$.
Acknowledgements This work was supported by the German Federal Ministry of Education and Research (BMBF grant 01LA9837/9) and the Volkswagen Foundation. FJ thanks the Electric Power Research Institute, Palo Alto, USA, and the Swiss National Science Foundation for their support. We thank also M. Grunert for help with the figures.

\section{References}

Bacastow R, Keeling CD (1973) Atmospheric carbon dioxide and radiocarbon in the natural carbon cycle, ii, changes from a.d. 1700 to 2070 as deduced from a geochemical reservoir. In: Woodwell GM, Pecan EV (eds) Carbon and the biosphere. US Department of Commerce, Springfield, Va, pp 86-135

Bruckner T, Petschel-Held G, Tóth FL, Füssel H-M, Helm C, Leimbach M, Schellnhuber H-J (1999) Climate change decisionsupport and the tolerable windows approach. Env Model Assess 4: 217-234

Caldeira K, Kasting J (1993) Insensitivity of global warming potentials to carbon dioxide emissions scenarios. Nature 366 : 251-253

Claussen M, Kubatzki C, Brovkin V, Ganopolski A, Hoelzmann P, Pachur H-J (1999) Simulation of an abrupt change in saharan vegetation in the mid-holocene. Geophys Res Lett 26(14): 2037 2040

Cline W (1992) The economics of global warming. Institute of International Economics, Washington DC

Cubasch U, Hasselmann K, Höck H, Maier-Reimer E, Mikolajewicz U, Santer B, Sausen R (1992) Time-dependent greenhouse warming computations with a coupled oceanatmosphere model. Clim Dyn 8: 55-69

Enting IG, Wigley TML, Heimann M (1994) Future emissions and concentrations of carbon dioxide: key ocean/atmosphere/land analyses. Techn Rep 31, CSIRO, Division of Atmospheric Research, Melbourne, Victoria, Australia

Friedlingstein P, Bopp L, Ciais P, Dufresne J, Fairhead L, LeTreut H, Monfray P, Orr J (2001) Positive feedback between future climate change and the carbon cycle. Geophys Res Lett 28(8): 1543-1546

Friedlingstein P, Fung I, Holland E, John J, Brasseur G, Erickson $\mathrm{D}$, Schimel D (1995) On the contribution of $\mathrm{CO}_{2}$ fertilization to the missing biospheric sink. Global Biogeochem Cycles 9(4): $541-556$

Füssel H-M, van Minnen JG (2000) Deriving climate protection targets from guard-rails for the preservation of terrestrial ecosystems. Integr Assess (in press)

Ganopolski A, Kubatzki C, Claussen M, Brovkin V, Petukhov V (1998) The influence of vegetation-atmosphere-ocean interaction on climate during the mid-holocene. Science 280: 19161919

Gayler V, Claussen M (1997) The greening of the sahara during the mid-holocene: results of an interactive atmosphere-biome model. Global Ecol Biogeogr Lett 6: 369-377

Harvey L (1989) Managing atmospheric $\mathrm{CO}_{2}$. Clim Change 15: $343-381$

Hasselmann K, Hasselmann S, Giering R, Ocaña V, Storch HV (1997) Sensitivity study of optimal $\mathrm{CO}_{2}$ emission paths using a simplified structural integrated assessment model (siam). Clim Change 37: 345-386

Hasselmann K, Sausen R, Maier-Reimer E, Voss R (1993) On the cold start problem in transient simulations with coupled atmosphere-ocean models. Clim Dyn 9: 53-61

Huntingford C, Cox P (2000) An analogue model to derive additional climate change scenarios from existing gcm simulations. Clim Dyn 16: 575-586

IPCC (1990) Climate change, the IPCC scientific assessment. IPCC/WMO/UNEP Cambridge University Press, Cambridge, $\mathrm{UK}$

IPCC (1992) Climate change the supplementary report to the IPCC scientific assessment combined with supporting scientific 
material. IPCC/WMO/UNEP Cambridge University Press, Cambridge, UK

IPCC (1995) Climate change 1994, radiative forcing of climate change and an evaluation of the IPCC is 92 emission scenarios. IPCC/WMO/UNEP Cambridge University Press, Cambridge, $\mathrm{UK}$

IPCC (1996) Climate change 1995, impacts, adaptations and mitigation of climate change: Scientific-technical analyses. contribution of working group ii to the second assessment report of the IPCC. IPCC/Cambridge University Press, Cambridge, UK

IPCC (2000) (Nakićenović et al.) Special report on emission scenarios. IPCC (in press)

Joos F, Bruno M (1998) Long-term variability of the terrestrial and oceanic carbon sinks and the budgets of the carbon isotopes ${ }^{13} \mathrm{C}$ and ${ }^{14} \mathrm{C}$. Global Biogeochem Cycles 12: 277-295

Joos F, Bruno M, Fink R, Siegenthaler U, Stocker T, LeQuéré C, Sarmiento J (1996) An efficient and accurate representation of complex oceanic and biospheric models of anthropogenic carbon uptake. Tellus 48B: 397-417

Joos F, Plattner G-K, Stocker T, Marchal O, Schmittner A (1999) Global warming and marine carbon cycle feedbacks on future atmospheric $\mathrm{CO}_{2}$. Science 284: 464-467

Keeling R, Piper S, Heimann M (1996) Global and hemispheric $\mathrm{CO}_{2}$ sinks deduced from changes in atmospheric $\mathrm{O}_{2}$. Nature 381: 218-221

Keeling R, Shertz S (1992) Seasonal and interannual variations in atmospheric oxygen and implications for the global carbon cycle. Nature 358: 723-727

Kicklighter D, Bruno M, Dönges S, Esser G, Heimann M, Helfrich J, Ift F, Joos F, Kaduk J, Kohlmaier G, McGuire D, Melillo J, Meyer R, Moore B, Nadler A, Prentice I, Sauf W, Schloss A, Sitch S, Wittenberg U, Würth G (1999) A first-order analysis of the potential role of $\mathrm{CO}_{2}$ fertilization to affect the global carbon budget: a comparison of four terrestrial biosphere models. Tellus 51B: 343-366

Knorr W (1997) Satellitengestützte Fernerkundung und Modellierung des globalen $\mathrm{CO}_{2}$-Austauschs der Landvegetation: Eine Synthese. PhD Thesis, Universität Hamburg, Max-PlanckInstitut für Meteorologie, Examensarbeit 49

Maier-Reimer E Hasselmann K (1987) Transport and storage of $\mathrm{CO}_{2}$ in the ocean - an inorganic ocean-circulation carbon cycle model. Clim Dyn 2: 63-90

Maier-Reimer E, Mikolajewicz U, Winguth A (1996) Future ocean uptake of $\mathrm{CO}_{2}$ : interaction between ocean circulation and biology. Clim Dyn 12: 711-721

Matear R, Hirst A (1999) Climate change feedback on the future oceanic $\mathrm{CO}_{2}$ uptake. Tellus 51B: 722-733

Meyer R, Joos F, Esser G, Heimann M, Hooss G, Kohlmaier G, Sauf W, Voss R, Wittenberg U (1999) The substitution of high-resolution terrestrial biosphere models and carbon sequestration in response to changing $\mathrm{CO}_{2}$ and climate. Global Biogeochem Cycles 13: 785-802

Myhre G, Highwood EJ, Shine KP, Stordal F (1998) New estimates of radiative forcing due to well mixed greenhouse gases. GRL 25: 2715-2718

Nakićenović N, Grübler A, McDonald A (eds) (1998) In: Global Energy Perspectives. International Institute for Applied System Analysis/World Energy Council, Cambridge University Press, Cambridge, UK

Oeschger H, Heimann M (1983) Uncertainties of predictions of future atmospheric $\mathrm{CO}_{2}$ concentrations. J Geophys Res 88: $1258-1262$
Petschel-Held G, Schellnhuber H-J, Bruckner T, Tóth FL, Hasselmann K (1999) The tolerable windows approach: theoretical and methodological foundations. Clim Change 41: 303-331

Plattner G-K, Joos F, Stocker T, Marchal O (2001) Feedback mechanisms and sensitivities of ocean carbon uptake under global warming. Tellus B, in press

Revelle R, Suess H (1957) Carbon dioxide exchange between atmosphere and ocean and the question of an increase of atmospheric $\mathrm{CO}_{2}$ during the past decades. Tellus 9: 18-27

Santer B, Brüggemann W, Cubasch U, Hasselmann K, Höck H, Maier-Reimer E, Mikolajewicz U (1994) Signal-to-noise analysis of time-dependent greenhouse warming experiments. part 1: pattern analysis. Clim Dyn 9: 267-285

Sarmiento J, Hughes T, Stouffer R, Manabe S (1998) Simulated response of the ocean carbon cycle to anthropogenic climate warming. Nature 393: 245-252

Sarmiento J, Orr J, Siegenthaler U (1992) A perturbation simulation of $\mathrm{CO}_{2}$ uptake in an ocean general circulation model. J Geophys Res 97 C3: 3621-3645

Sarmiento J, Sundquist E (1992) Revised budget for the oceanic uptake of anthropogenic carbon dioxide. Nature 356: 589-593

Schimel D, Grubb M, Joos F, Kaufmann R, Moos R, Ogana W, Richels R, Wigley T (1997) Stabilization of atmospheric greenhouse gases: physical, biological, and socio-economic implications IPCC Tech Pap III, Geneva

Schlesinger M, Andronova N, Ghanem A, Malyshev S, Rozanov E, Wang W, Yang F (1998) Geographical scenarios of greenhouse-gas and anthropogenic-sulfate-aerosol induced climate changes. http://crga.atmos.uiuc.edu/publications/geoscen_abs. html

Schlesinger W (1993) Response of the terrestrial biosphere to global climate change and human perturbation. In: Rozema J, Lambers $\mathrm{H}$, van de Geijn S, Cambridge $\mathrm{M}$ (eds) $\mathrm{CO}_{2}$ and biosphere, reprinted from Vegetatio, volume 104/105, pp 295305. Kluwer Academic Publishers, Dadrecht

Sellers P, Bounoua L, Collatz G, Randall D, Dazlich D, Los S, Berry J, Fung I, Tucker C, Field C, Jensen T (1996) Comparison of radiative and physiological effects of doubled atmospheric $\mathrm{CO}_{2}$ on climate. Science 271: 1402-1406

Siegenthaler U (1983) Uptake of excess $\mathrm{CO}_{2}$ by an outcrop-diffusion model of the ocean. J Geophys Res 88: 3599-3608

Siegenthaler U, Oeschger H (1978) Predicting future atmospheric carbon dioxide levels. Science 199: 388-395

Siegenthaler U, Oeschger $\mathrm{H}$ (1987) Biospheric $\mathrm{CO}_{2}$ emissions during the past 200 years reconstructed by deconvolution of ice core data. Tellus 39B: 140-154

Siegenthaler U, Sarmiento J (1993) Atmospheric carbon dioxide and the ocean. Nature 365: 119-125

Tans P, Fung I, Takahashi T (1990) Observational constraints on the global atmospheric $\mathrm{CO}_{2}$ budget. Science 247: 1431-1438

Thompson M, Randerson J (1999) Impulse response functions of terrestrial carbon cycle models: method and application. Global Change Bio 5: 371-394

Voss R, Mikolajewicz U (2000) Long-term climate changes due to increased $\mathrm{CO}_{2}$ concentration in the coupled atmosphereocean general circulation model echam3/lsg. Clim Dyn (in press)

Voss R, Sausen R, Cubasch U (1998) Periodically synchronously coupled integrations with the atmosphere-ocean general circulation model echam3/lsg. Clim Dyn 14: 249-266 